\title{
Revisão das micro- e macrounidades de tradução na abordagem processual e pragmática da pesquisa de tradução
}

\author{
Revisit the micro and macro translation units in the procedural and \\ pragmatic approach of translation research
}

Kyoko Sekino

\begin{tabular}{|c|c|}
\hline $\begin{array}{l}\text { RESUMO: O presente estudo revê a } \\
\text { importância da unidade de tradução } \\
\text { processual. Retoma a análise das micro e } \\
\text { macrounidades de tradução (ALVES; } \\
\text { VALE, 2009; 2011), recuperadas por meio } \\
\text { da aplicação MicroUnitsAPP, para } \\
\text { observar a importância do contexto na } \\
\text { tradução com base na abordagem } \\
\text { pragmática da tradução (GUTT; 2000). } \\
\text { Com o uso dos dados de um participante, } \\
\text { P3, coletados por meio do Translog-II no } \\
\text { estudo de Minatogau (2018), envolvendo } \\
\text { o par linguístico japonês-português, } \\
\text { realizou-se, manualmente, uma análise } \\
\text { da distribuição de unidades de tradução, } \\
\text { distinguindo-se micro e macrounidades } \\
\text { de tradução. Identificou-se que, dentre } 96 \\
\text { microunidades de tradução, } 70 \text { pertencem } \\
\text { a uma única macrounidade. Após essa } \\
\text { macrounidade, a produção textual de P3 } \\
\text { tornou-se mais rápida e mais linear, o que } \\
\text { remete à importância de um contexto } \\
\text { esclarecido na tarefa de tradução. } \\
\text { Conclui-se, com base nos resultados, que } \\
\text { a análise de dados das unidades de } \\
\text { tradução ainda apresenta uma } \\
\text { característica distinta em relação ao } \\
\text { processo de tradução como um todo, } \\
\text { especialmente a partir de uma abordagem } \\
\text { pragmática. Isso pode explicar a } \\
\text { distribuição do esforço cognitivo na } \\
\text { reconstrução do contexto do texto-fonte }\end{array}$ & $\begin{array}{l}\text { ABSTRACT: The present study examines } \\
\text { the importance of procedural translation } \\
\text { units. It revises the notion of micro and } \\
\text { macro translation units (ALVES; VALE, } \\
\text { 2009; 2011) by using application } \\
\text { MicroUnitsAPP to explore the } \\
\text { importance of context in translation from } \\
\text { a pragmatic translation approach (GUTT; } \\
\text { 2000). Building on data of one single } \\
\text { participant, P3, as collected through } \\
\text { Translog-II by Minatogau (2018), a } \\
\text { manual analysis was carried out of the } \\
\text { distribution of translation units, } \\
\text { especially their distribution in micro and } \\
\text { macro translation units. A total of } 96 \\
\text { micro translation units was identified, out } \\
\text { of which } 70 \text { belonged to one single macro } \\
\text { translation unit. After this macro } \\
\text { translation unit, P3's text production } \\
\text { became faster and more linear, pointing } \\
\text { to the importance of context in translation } \\
\text { tasks. This seems to show that the analysis } \\
\text { of translation units still presents a distinct } \\
\text { feature in comparison to the entire } \\
\text { translation process, especially from a } \\
\text { pragmatic approach. This may also } \\
\text { explain the distribution of cognitive effort } \\
\text { in the reconstruction of the source text's } \\
\text { context for translation and point to the } \\
\text { need to formulate a procedural } \\
\text { translation unit editor. }\end{array}$ \\
\hline
\end{tabular}


para a tradução e apontar para uma necessidade de se elaborar um editor de unidades de tradução processual.

PALAVRAS-CHAVE: Abordagem cognitiva processual. Pragmática. Micro e macrounidades de tradução. KEYWORDS: Cognitive and procedural approach. Pragmatics. Micro and macro Metodologia.

\section{Introdução}

O objetivo deste artigo é rever a noção de unidade de tradução - inicialmente, de maneira geral e, posteriormente, com base na abordagem processual - e, por fim, rever o método da análise do processo de tradução. Busca-se, assim, recuperar o valor, a noção e a aplicabilidade dos conceitos de micro e macrounidades de tradução (ALVES; VALE, 2009; 2011; ALVES; GONÇALVES, 2013). Trata-se de uma discussão retrospectiva e perspectiva de uso mais ampliado das micro e macrounidades de tradução (UTs).

O motivo deste trabalho originou-se da inquietação diante da subutilização da unidade de tradução em investigações de cunho processual, em virtude da mudança metodológica de algumas ferramentas. Trata-se de um anseio pelo reconhecimento do valor dos trabalhos realizados no Laboratório Experimental da Tradução (LETRA) da Universidade Federal de Minas Gerais (UFMG), a partir dos artigos de Alves e Vale (2009; 2011), os quais, inicialmente, apresentaram a análise das micro e macrounidades de tradução por meio do Translog. Esse instrumento de dados, criado, inicialmente, por Jakobsen e Schou (JAKOBSEN, 1999), experimentou algumas renovações e, a partir de 2011, foi transformado em Translog-II, com uma nova arquitetura computacional. Na década de 2000, as micro e macrounidades de tradução foram concebidas e exploradas por meio das versões antigas do programa, como o Translog 2006, que eram utilizadas para fins de experimentação no LETRA/UFMG. A partir do arquivo gerado pelo Translog, a gravação do processo de tradução era editada no Litterae 
(ALVES; VALE, 2011), um editor que processa a gravação em formato XML, para analisar o processo de tradução, segmentado em unidades de tradução, e realizar a edição delas em microunidades que compõem macrounidades de tradução.

Carl (2014) apresenta o Translog-II como um novo desdobramento metodológico e tecnológico para a coleta e análise de dados, quando enfatiza a sua potência na análise do comportamento da leitura do tradutor por meio do rastreamento ocular. Esse novo meio de coleta de dados, sem dúvida, redireciona a pesquisa do processo de tradução. No entanto, ainda há um espaço a ser explorado sem o uso do rastreamento ocular. Satisfatoriamente, o Translog-II é útil para coletar dados do processo de tradução mesmo sem recursos oculares. Haja vista que a mudança metodológica sempre traz novas perspectivas de resultados, Jakobsen (2011) exprime suas reflexões sobre o que se espera ao usar um rastreador ocular. Este revela o que antes apenas podíamos inferir, como, por exemplo, o que o tradutor faz durante a pausa: agora, o comportamento de leitura dos informantes da pesquisa é identificado, podendo-se classificá-lo em diversos estilos de trabalho, como o do tradutor-revisor on-line (CARL; DRAGSTED; JAKOBSEN, 2011).

Ao mesmo tempo, verifica-se que a tradução é a reconstrução de um texto, para uma língua-alvo, a partir de um texto-fonte (TF). Nesse sentido, a gravação do acionamento de teclas e do mouse, sem rastreamento ocular, ainda revela um processo além do comportamento textual e linguístico. Para esse fim, rebuscar-se-á o uso das micro e macrounidades de tradução, como exploradas no LETRA/UFMG.

Este artigo procura expor a relação da unidade de tradução com a pesquisa de tradução na abordagem processual e com a mudança metodológica a partir de uma breve revisão de literatura. Apresentará, também, a abordagem processual, principalmente, de Alves (a partir de 1995 em diante) e Alves e Gonçalves (2003; 2007; 2013) sobre a visão pragmática, especialmente no que diz respeito a inferências através de explicatura e implicatura, conforme definidas na Teoria de Relevância (SPERBER; 
WILSON, 1986), e a esforço cognitivo no processo de tradução (GUTT, 2000). Depois, com base em um experimento de Minatogau (2018), exploram-se os dados de um participante referentes às suas micro e macrounidades de tradução.

Mais especificamente, esta pesquisa trata da observação do grau da compreensão que um participante tem de um texto escrito em língua japonesa, a qual possui ordens estruturais distintas daquelas do português brasileiro (SHIBATANI; 2009). Com base neste estudo, busca-se perceber a mudança cognitiva do participante, recuperando a noção de micro e macrounidades de tradução como pistas da mudança cognitiva sobre o contexto. Nesse sentido, trata-se de um estudo analítico-exploratório, que busca ampliar a possibilidade da análise do processo de tradução com o uso de unidades de tradução processuais e de sua aplicabilidade junto a aprendizes de segunda língua (L2).

\section{Revisão de literatura}

\subsection{O início da investigação do processo de tradução}

Apresenta-se, neste espaço, uma breve revisitação retrospectiva da metodologia de pesquisa do processo de tradução. Rodrigues $(1997 ; 2002)$ sistematizou as pesquisas iniciais e principais com a abordagem processual e realizou uma meta-análise. Ele identificou, como ponto de partida, uma pesquisa apresentada por Krings (1986), que compara o processo de oito estudantes alemães, de francês avançado, em duas tarefas de tradução: uma para a L1 e a outra para a L2. Antes dessa pesquisa, o processo de tradução era considerado como "um fator secundário dentro do ato tradutório, e não como um fator determinante" (RODRIGUES, 1997, p. 56).

Krings (1986) trouxe uma metodologia, na época, utilizada predominantemente na psicologia, o Thinking Aloud Protocol (TAP), verbalização do pensamento em voz alta, para seu projeto de investigação de tradução. Ericsson e Simon (1993) sugerem que o TAP é capaz de trazer o que está sendo processado na mente enquanto alguma 
tarefa está sendo processada. Os trechos verbalizados formam uma sequência de pensamentos, os quais são considerados atividades cognitivas durante a realização completa da tarefa. Nessa fase inicial, é o uso do protocolo verbal que caracteriza a pesquisa processual, considerando-a como a investigação do processo mental, com uma abordagem empírico-dedutiva. Essa investigação processual possibilita ao pesquisador reconstruir "a realidade através dos seus dados e apresentar no final um conjunto de conclusões que possuem caráter hipotético" (RODRIGUES; 1997, p. 57).

Krings (1986) observa, mediante protocolos verbais, problemas de tradução, seus respectivos indicadores e as estratégias usadas pelos participantes para contornar esses problemas. A utilização desse instrumento abriu uma nova linha de pesquisa nos Estudos de Tradução, chamada de abordagem psicolinguística da tradução ou abordagem processual de tradução. O surgimento dessa nova linha respondeu a uma insatisfação com os modelos teóricos outrora desenvolvidos, os quais eram desprovidos de embasamento empírico e da presença do tradutor (RODRIGUES, 2002, p. 24).

Após uma meta-análise de 35 pesquisas processuais realizadas a partir da primeira por Krings (1986), Rodrigues (2002) concluiu que há alguns modelos distintos, mesmo que haja amplo grau de variedade em virtude da individualidade dos participantes da pesquisa. Em geral, os pesquisadores observam várias estratégias de tradução relacionadas à solução de problemas. Alguns termos foram criados ao longo das aplicações das pesquisas processuais: por exemplo, processos automáticos e processos estratégicos, os quais constam no modelo de Königs (1986; 1987, apud RODRIGUES, 2002) e foram denominados, posteriormente, pelo próprio pesquisador como Adhoc-Block e Rest-Block. O primeiro refere-se aos processos automatizados que não são acessíveis ao processo introspectivo; o segundo, a processos acessíveis a uma investigação introspectiva. 
Nesse modelo, identifica-se o uso do termo "unidade de tradução"; porém, sem apresentar um conceito específico. Alves (1995), que expande o modelo de Königs, cria uma nova categoria de processamento classificada conforme o contexto ou a situação. Além dessa nova observação, o modelo de Alves é caracterizado pelas interações da memória de curto prazo com a de longo prazo no processo da tradução. Para Alves (1995), o Adhoc-Block, um dos três tipos de processamento, influenciado por informações contextuais ou não, é processado, primeiro, na memória de curto prazo. Se não é possível produzir uma tradução, essa unidade de tradução é processada no Rest-Block por meio da busca de mais informações contextuais, disponíveis na memória de longo prazo e/ou com apoios externos. Essa terceira categoria está relacionada à Teoria da Relevância, de Sperber e Wilson (1986), conforme descrita na seção 2.5 .

\subsection{Gravação de acionamento de teclas e mouse (key logging)}

Outro instrumento de pesquisa é o de gravação do processo de tradução. Jakobsen e Schou (JAKOBSEN, 1999) apresentaram um instrumento que grava todas as atividades relativas à criação do texto de tradução, o Translog, criado para observar essa construção textual, com seus respectivos tempos de produção e pausas, por meio da gravação a partir das teclas acionadas e do movimento do mouse (key logging). Após a gravação, o processo pode ser repetido no modo replay, possibilitando, aos pesquisadores, a observação do processo e a análise dos dados armazenados no instrumento. Jakobsen (1999) também recomenda a triangulação na análise de dados, os quais devem ser coletados por diferentes instrumentos para sustentar a qualidade científica dos resultados. Alves $(2001 ; 2003)$ e Hansen (2008) igualmente fazem essa recomendação.

Jakobsen (2002) observa que, com o uso simultâneo de TAP e Translog, há um aumento significativo no tempo de realização da tarefa de tradução. Esse resultado 
refuta, ao menos para a tradução, a hipótese de Ericsson e Simon (1993) no que diz respeito à não ocorrência de interferência na verbalização durante a realização das tarefas. Jakobsen (2002) ainda identifica a existência de três fases distintas no processo de tradução: orientação (i.e., do contato inicial com o texto-fonte até a digitação da primeira tecla); redação (i.e., da digitação da primeira tecla até a primeira versão completa do texto-alvo); e revisão (da primeira versão completa do texto-alvo até a entrega do texto traduzido.

Jakobsen (2002) postulava a leitura integral do texto-fonte como o comportamento distintivo do profissional. No entanto, posteriormente, foram identificados, em um experimento conduzido com o uso do rastreamento ocular, diversos estilos de processamento entre os tradutores profissionais (CARL; DRAGSTED; JAKOBSEN, 2011). Por exemplo, alguns tradutores leem o texto-fonte na íntegra antes de iniciarem a tradução; outros sequer revisam a tradução parcial na fase de redação, traduzindo rápido, com a qualidade de rascunho na fase de redação, e só refinando a tradução na fase de revisão. Em português brasileiro, alguns estudos tratam do mesmo tema (e.g., PAGANO; MAGALHÃES; ALVES, 2005; FERREIRA, 2012; 2013; SCHMALTZ et al, 2016, dentre outros).

\subsection{Unidade de tradução e noção da pausa no âmbito do Translog}

Inicialmente, Holmes (1972) e outros pesquisadores da tradução (e.g., MOUNIN, 1963; NIDA; TABER, 1964, NIDA, 1969; TOURY, 1991; 1995; NEWMARK, 1988; HERMAN, 1999) tiveram uma preocupação com a cientificidade da pesquisa em tradução (LANGENDOEN, 2013). Na investigação científica, em geral, sempre há uma unidade mínima que constrói o universo do objeto da pesquisa (BALLARD, 2010). Por analogia, os pesquisadores de tradução também criaram o termo, unidade de tradução (UT). No entanto, sua definição difere de acordo com a abordagem da pesquisa. $\mathrm{O}$ mapa da perspectiva de pesquisas da tradução (HOLMES; 1972, TOURY; 1991) 
demonstra, já na época, a abrangência e a potência crescente das subáreas dos Estudos de Tradução. Da mesma forma, há diversas definições de UT desencadeadas pelo avanço dos Estudos de Tradução.

Dragsted (2004) organiza os conceitos de unidade de tradução em três grupos:

1) equivalência entre língua-fonte (LF) e a língua-alvo (LA), em que uma palavra, um conjunto de palavras em sequência ou algumas unidades gramaticais, no par LF e LA, são consideradas como UT. Essa discussão foi iniciada por Vinay e Darbelnet (1958) e Catford (1964), seguidos por vários outros pesquisadores;

2) Um (ou alguns) parágrafo(s) forma(m) uma unidade de significado do TF, conforme Nida (1969), Bassnett-McGuire (1991) e outros; e

3) A unidade de tradução é uma unidade flexível. Demonstra o funcionamento da memória de curto prazo do tradutor, conforme Bell (1991) e Zhu (1999), dentre outros. As unidades no par TF e TA, em um segmento textual, podem ser maior ou menor, dependendo da capacidade do tradutor (e.g., TOURY, 1995).

Os métodos de investigação geram certos impactos na perspectiva de pesquisa, criando uma nova área com potencial crescimento. Com surgimento do Translog, possibilitou-se aos pesquisadores a criação de um novo paradigma de análise: uma nova definição da UT na abordagem processual. Dragsted (2004) investigou as segmentações da tradução, mediante observação de como e quando o tradutor pausa durante a tarefa. A segmentação textual representa o tamanho de uma extensão textual processada, sem pausa, por indivíduo. O segmento é marcado por duas pausas, inicial e final, isto é, a segmentação se refere a uma extensão de texto que a memória de trabalho humana é capaz de processar sem parar. Ela é interpretada como unidade de tradução processual. Observa-se, então, que a pausa no processo de tradução assume um papel relevante. 
Jakobsen (2005) ressalta essa importância como dado para análise após observar o comportamento das pausas realizadas ao longo da tarefa de tradução, bem como a correlação delas com o grau de expertise dos participantes. Os resultados da sua pesquisa sugerem que os profissionais têm uma segmentação maior que os estudantes, em termos de comprimento dos segmentos. Isso, possivelmente, demonstra a superioridade do funcionamento da memória de trabalho dos profissionais. Jakobsen ainda identifica que há um limite máximo de desempenho do tradutor experto. Essa identificação sustenta parcialmente uma hipótese levantada por Künzli (2001; 2004), a de que o desempenho máximo (peak performance) é observado apenas no campo especializado em que o tradutor está envolvido. Metodologicamente, Jakobson, com base em Dragsted (2004; 2005), sugere o uso de 2,4 segundos de pausa exclusivamente para observar esse comportamento dos expertos na mesma configuração experimental.

Dragsted $(2004 ; 2005)$ sustenta sua concepção de pausa alinhada à da produção de texto de Schilperoord (1996): pausas na produção textual representam processos cognitivos envolvidos na busca na memória de longo prazo. Pausas mais longas demonstram mais esforço cognitivo despendido para produzir uma nova unidade textual e para compreensão. Consequentemente, pode-se dizer que as pausas longas são indicadores de mais esforço cognitivo do que as curtas. Essa observação coincide um estudo da oralidade, no qual Good e Butterworth (1980 apud DRAGSTED, 2005) postulam: quanto mais a dificuldade conceitual aumenta em um enunciado, mais tempo de pausa é requerido. Desde Jakobson (2005), o tempo de pausa de 2,4 segundos tem sido amplamente utilizado na investigação de expertise, como em Alves e Gonçalves (2007; 2013), Koglin (2015), Fonseca (2016), Ferreira et al. (2016), Da Silva et al. (2017).

Alves e Vale (2009) experimentam o uso de 1, 3 e 5 segundos para uma exploração metodológica da análise linear e concluem que cada tempo de pausa 
apresenta diferentes comportamentos processuais. Isso significa que, se um analisador de dados do Translog desejar, é possível estabelecer um valor de pausa de acordo com o objetivo da pesquisa. Alves et al. (2010) adotam um segundo para o estudo de mudança de tradução (translation shift). Ehrensberger-Dow e Perrin (2013), por sua vez, usam o valor de 3 segundos para a pausa, conforme era prática comum (e.g., DA SILVA, 2007; ALVES; VALE, 2009; SEKINO, 2015). Já o estudo de Koehn e Haddow (2009) usa três valores diferentes: de 1, 3 e 10 segundos para observar o comportamento dos pós-editores de diferentes plataformas de pós-edição sem a apresentação do embasamento teórico do valor dessa pausa. Na pesquisa de Finger-Kratochvil (2010) o valor de 0,01 segundo é adotado no estudo de leitura e compreensão. Do mesmo modo, segundo Kumpulainen (2015), o valor de 0,01 segundo é adotado nos estudos de tradução de Immonen (2006; 2011).

A partir dessa revisão, pode-se dizer que o valor de pausa é arbitrário de acordo com a análise de segmentações. Kumpulainen (2015) explica essa variedade devido à diferença da configuração metodológica, experimental e analítica e aos objetivos de estudo. Ademais, há impedimentos tecnológicos para assegurar a exatidão da mensuração.

Há estudos que investigam pausas curtas menor que um segundo: se estas ocorrem consecutivamente para um evento completo, i. e., digitar uma palavra com diversas pausas curtas. Lacruz et al. (2012) e Lacruz e Shreve (2014) argumentam que a relevância do esforço cognitivo com relação à pausa não é apenas relacionada ao tempo de pausa em si, mas à densidade envolvida na pausa. Esses autores sustentam que a agregação sucessiva de pausas de 0,5 segundos pode indicar esforço cognitivo.

\subsection{Conceitos relevantes da Psicologia e da Psicolinguística}

Segundo Baddeley (2007), a memória de trabalho (working memory), refere-se à parte do sistema do armazenamento temporal, bem como da manipulação de input 
sensorial e das informações advindas da memória de longo prazo, a fim de realizar tarefas complexas. Dragsted (2004) e Hvelplund (2011) consideram que a memória de trabalho é central para a atividade de tradução, visto que esta consiste em várias tarefas complementares, incluindo leitura, compreensão e produção de texto. Baddeley e Hirth (1974) defendem a função da memória de trabalho que não apenas armazena, temporariamente, as informações, mas as processa ativamente dentro de um sistema maior da memória humana, como a memória de longo prazo, que é responsável pelo armazenamento de informações por um tempo mais amplo e constitui a estrutura do armazenamento. Cooper (1998) entende a memória de trabalho como uma parte da nossa mente que fornece nossa consciência. Ela é o veículo que nos capacita a pensar (lógica e criativamente), resolver problemas e expressar. Em termos de seus limites, o estudo de Miller (1956) sugere que ela é capaz de tratar, sete elementos, em média, de informações simultaneamente, embora não especificou quais são esses elementos e respectiva quantidade.

Nesse processamento nas memórias, sobretudo na memória de trabalho, tarefas que envolvem a tomada de decisão requerem esforço. Grosso modo, de acordo com Westbrook e Braver (2015), o esforço refere-se ao grau de empenho em tarefas exigentes. Alto grau de empenho pode aprimorar o desempenho por meio de atenção, embora o esforço não se resuma a atenção. Tarefas que demandam esforço são complexas, porque não são realizadas mecanicamente. Elas necessitam de respostas controladas e envolvem processos sequenciais e limitados em termos de capacidades. Os referidos autores sustentam, também, que "esforço cognitivo não é idêntico a dificuldade, motivação, atenção ou controle cognitivo" $\left(2015\right.$, p.3) ${ }^{1}$; é, na verdade, "um custo que compensa o valor de estratégias cognitivas por outro lado desejáveis"2 2 .

1 (original) Cognitive effort is thus not identical with difficulty, motivation, attention, or cognitive control.

2 (original) (...) a cost offsetting the value of otherwise desirable cognitive strategies. 
No contexto da tradução, esforço cognitivo pode ser entendido como uma operação cognitiva que envolve o planejamento e a tomada de decisão na busca por solução de problemas. Kumpulainen (2015) relata diversas pesquisas relacionadas sobre pausas, observadas no processamento de língua(s) em diferentes modos (falar, copiar, redigir, traduzir, dentre outros), como instâncias de resolução de problemas para se tomar uma decisão. Tyler e colaboradores (1979) realizam experimentos para medir o esforço cognitivo profundo baseados na hipótese de que a memória de trabalho pode processar diversas tarefas simultaneamente em vários níveis de processamento. A tradução consiste em múltiplas tarefas que envolvem, além de leitura, compreensão e produção textual, processamento bilíngue e a tomada de decisão. Essas tarefas ocorrem concomitantemente, o que é uma condição propícia para a investigação do esforço cognitivo. Ademais, na compreensão do TF, especialmente no âmbito experimental, tradutores precisam identificar o contexto do texto a partir do recorte usado no experimento. Nesse sentido, a inferência do contexto é outro fator relevante em termos de dispêndio de esforço cognitivo.

\subsection{Micro UT e macro UT}

Com relação à unidade de tradução, embora seja apenas uma definição interna de seu trabalho, Dragsted (2005) a define como “a extensão de texto compreendida/produzida entre duas pausas que duram por um tempo"3 (p. 52). Alves (2000) apresenta uma definição flexível da UT para que cada estudo do processo de tradução esteja adequado de acordo com a operacionalidade.

UNIDADE DE TRADUÇÃO é um segmento do texto de partida, independente de tamanho e forma específicos, para o qual, em um dado momento, se dirige o foco de atenção do tradutor. Trata-se de um segmento em constante transformação que se modifica segundo as

3 (original) the text string comprehended/produced between two pauses of a certain duration. 
necessidades cognitivas e processuais do tradutor. A UNIDADE DE TRADUÇÃO pode ser considerada como a base cognitiva e o ponto de partida para todo o trabalho processual do tradutor. Suas características individuais de delimitação e sua extrema mutabilidade contribuem fundamentalmente para que os textos de chegada tenham formas individualizadas e diferenciadas. O foco de atenção e consciência é o fator direcionador e delimitador da UNIDADE DE TRADUÇÃO e é através dele que ela se torna momentaneamente perceptível. (ALVES, 2000, p. 38, ênfase do autor)

Definido o tempo de pausa para uma análise, as UTs representam o processamento segmentado na elaboração do texto-alvo (TA) e demonstram processos não lineares, já que algumas unidades complementam outras anteriores e também são retomadas às unidades já produzidas. A partir dessa observação, Alves e Vale (2009; 2011) distinguem as UTs como microUTs e macroUTs. As microUTs são, cada uma, o fluxo contínuo da produção do texto, que pode envolver a leitura do texto-fonte e dos segmentos já traduzidos, enquanto uma macroUT é uma coleção de microUTs e abrange todas as produções intermediárias textuais que seguem o foco do tradutor no mesmo segmento do $\mathrm{TF}$, desde a primeira tentativa até o produto final, como aparece no texto da tradução. Em outras palavras, uma macroUT é agregada pelas microUTs e sua extensão textual se dá a partir das unidades anteriores, com o intuito de corrigir, de acrescentar, de deletar, de trocar a ordem etc. Isso significa que as macroUTs contêm unidades de edição, por meio das quais se consegue observar a mudança cognitiva e o esforço cognitivo do tradutor em determinado trecho do texto.

Alves e Vale (2011) desenvolveram o Litterae, um motor analítico de UTs, com o replay do Translog incorporado, para facilitar a edição das UTs durante a análise. Esse programa computacional corresponde exclusivamente ao Translog modelo 2006. No entanto, o Translog foi renovado e passou a incorporar a função do rastreamento ocular a partir da versão de Translog-II (CARL; 2012). Nessa nova versão, ficou indisponível a antiga opção de exibição linear do processo tradutório, o que suspendeu a extração facilitada de dados de micro e macroUTs. Mesmo assim, nossa intenção é 
ainda continuar com o método de análise de Alves e Vale (2009; 2011), adaptando-nos ao novo ambiente que o Translog-II oferece, de modo a revalorizar as micro e macroUTs.

Lacruz, Shreve e Angelone (2012) usam o termo "instância de edição completa (complete editing event)", o que é a coleção de edições segmentadas por pausas para formar um evento com diversas ações complementares. $\mathrm{O}$ evento pode ser referido como uma palavra. Considera-se um evento, em vez de três, quando uma palavra é inserida e pausada em três momentos. Essa observação destaca o papel agregador de pausas curtas como indicador de esforço cognitivo e sugere que uma pausa ou pausas totais não indiquem esforço cognitivo, mas, quando vinculada(s) a eventos de edição, pode(m) indicar pontualmente esforço despendido para completar um evento. Embora os autores tratem o assunto no âmbito da pós-edição, pode-se aplicá-lo à tradução. A abordagem da mensuração dos autores é consideravelmente semelhante à de Alves e Vale, em que um agregado de edições acompanhadas por pausas demonstra esforço cognitivo em um segmento textual processado pelo tradutor no fluxo de trabalho. Alves e Vale ressaltam que as micro e macro UTs apresentam o processo na sequência textual, segmentada pelas pausas, as quais podem ser aumentadas pelas sequências retomadas até o foco da tradução mudar para a próxima sequência.

\subsection{Abordagem pragmática}

Sperber e Wilson (1986) introduziram a Teoria da Relevância (TR), uma abordagem da pragmática que trata da natureza da comunicação e da questão psicológica no processo de interpretação desenvolvido na mente humana. Portanto, a TR focaliza a comunicação e a cognição humana, com base no pressuposto de que a compreensão dos enunciados não é apenas um processo de decodificação mecânica, 
mas uma atividade cognitiva que envolve inferências. Em síntese, o objetivo da TR é explicar como o receptor da comunicação infere o significado do emissor com base na evidência providenciada.

A inferência pode ser uma característica da TR, a qual não é manifesta, mas apenas processada na mente humana. Segundo Sperber e Wilson (1986), o significado da comunicação é dividido em explicatura e implicatura. O primeiro é a forma explícita de um enunciado codificado pela lógica; o segundo é a forma implícita de um enunciado não explícito. A implicatura deriva da inferência, tendo dois tipos: primeiro, suposições implicadas são um conjunto de pressupostos contextuais, os quais são empregados no processamento do enunciado; segundo, conclusões implicadas são um conjunto de implicaturas contextuais derivadas. O funcionamento da cognição acontece dessa forma, pois a cognição humana funciona na base do custobenefício.

A relevância é medida pelo receptor seguindo um procedimento cognitivo de custo-benefício. Sendo todos iguais, o receptor tende a selecionar a interpretação, a partir de uma gama de interpretações possíveis do mesmo enunciado no contexto ocorrente, que satisfaça as condições do melhor rendimento (efeitos cognitivos positivos) e menor esforço... ${ }^{4}$ (YUS; 2009, p. 762-763)

Gutt (2000) aplica a TR à tradução. De acordo com o autor, a TR pode ser uma teoria robusta para explicar a tradução, considerada por ele uma forma especial de comunicação que envolve três partes: o autor do texto original, o tradutor e os leitores do texto traduzido. Logo, é razoável assumir que a tradução deve seguir as regras gerais da comunicação, isto é, da TR. Desse modo, pode-se dizer que a tradução também é um processo de comunicação ostensivo-inferencial. Assim sendo, o tradutor

\footnotetext{
${ }^{4}$ (original) Relevance is measured by hearers by following a cognitive cost - benefit procedure. All things being equal, the hearer will tend to select the interpretation, from the range of possible interpretations of the same utterance in the current context, that satisfies the conditions of highest reward (positive cognitive effects) and least mental effort ...
} 
deve fazer inferências de acordo com o comportamento ostensivo do autor do texto original, perceber a eficiência de efeitos contextuais e demonstrar sua própria compreensão da intenção do autor original para os leitores-alvo, de modo que estes consigam fazer inferências, ou seja, a leitura de implicaturas, bem como ter efeitos contextuais. Yus (2009) sustenta que o tradutor, como um participante da comunicação, usa sua habilidade de comunicação para que crie pressupostos contextuais e disponibilize a relevância ótima. Dessa forma, a tradução consegue apresentar a semelhança interpretativa com base em aspectos relevantes.

\section{Estudo - metodologia}

Minatogau (2018), sob minha orientação, estudou a dificuldade, na tradução da língua japonesa para o português brasileiro, deparada pelos participantes em virtude da diferença estrutural e sintática entre essas línguas. Embora se use da tradução aplicou o experimento entre estudantes das últimas fases do curso de LicenciaturaJaponês em uma instituição de ensino superior no Brasil. Nela, 20 participantes fizeram, no programa Translog-II, a tradução de um texto curto e de nível intermediário (os detalhes da configuração do experimento de Minatogau encontramse abaixo). A autora realizou uma análise da oração modificadora (adjetiva), que ensejou "demora" em termos de tempo e de número de edições para a resolução de problemas tradutórios, isto é, demandou esforço cognitivo, como sugerido em diversos estudos (e.g., SCHAEFFER; CARL, 2014; SCHAEFFER et al., 2016; FERREIRA et al., 2016; DA SILVA et al., 2017; SCHMALTS, 2018). O resultado de Minatogau aponta, em relação a outras orações, maior tempo de processamento, maior número de pausas e maior número de microUTs para o processamento da oração adjetiva.

Em suma, Minatogau (2018) conclui que os participantes despenderam esforço cognitivo para resolver a tradução do trecho da oração adjetiva do japonês. Entretanto, como não existe um editor do desdobramento da análise linear oriunda do 
MicroUnitsAPP5 ${ }^{5}$ a pesquisadora implementou a análise apenas das UTs relacionadas com os trechos em questão; como resultado, seu estudo não envolveu o desdobramento de todas as UTs, o que possivelmente revelaria alguns fatores relevantes tanto processualmente quanto do ponto de vista da linguística e da pragmática. O objetivo deste artigo é demonstrar o desdobramento das UTs a partir da análise linear produzida pelo MicroUnitsAPP desse estudo por Minatogau (2018).

A língua japonesa possui propriedades diferentes do português-brasileiro no sistema de escrita. Minatogau mesma relata, ao aprender o japonês, suas dificuldades com a mudança da ordem sintática nesse par linguístico - especialmente, na oração adjetiva. Verificou, em seu trabalho, que é necessário um esforço cognitivo e processual extra em comparação com os outros segmentos textuais que não requereram troca da ordem. Essa diferença sintática reflete as diferenças das propriedades das línguas: no japonês, a oração modificadora, ou seja, a oração adjetiva, antecede o substantivo (SHIBATANI; 2009, NINOMIYA; 2014), enquanto, no português, a oração modificadora é posicionada depois do substantivo. Além disso, ressalta-se uma das principais diferenças entre as línguas nesse par: em relação à estrutura frasal, é SOV em japonês e SVO em português. Por exemplo:

A maçã que comprei ontem está doce.

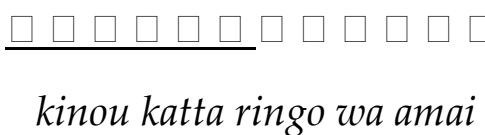

[ontem, comprei, maçã, WA <partícula-marcador de tema>, está doce]

\footnotetext{
${ }^{5}$ Aplicação desenvolvida por Gabriel Ed. da Silva, sob orientação do Prof. Dr. Igor Antônio Lourenço da Silva, no âmbito de um projeto de Bolsa de Graduação (2014PBG000883) na Universidade Federal de Uberlândia (UFU). De código aberto, a aplicação está disponível em https://github.com/gabrieleduardo/MicroUnits.
} 
Compreender uma sentença japonesa com oração adjetiva como a supracitada demanda esforço e atenção para trocar a ordem sintática. Minatogau (2018) problematizou a compreensão da oração adjetiva, que requeria dos estudantes um esforço cognitivo. Foi valorado o método da tradução, por meio do Translog-II, a fim de verificar as dificuldades dos estudantes na forma quantificada, já que se trata de esforço cognitivo relativo ao processo de tradução. Após a coleta, gerou-se a análise linear a partir do MicroUnitsAPP (DA SILVA, 2016). Ressalta-se, contudo, que, no estudo de Minatogau (2018), foram analisados o tempo despendido e o número de micro e macroUTs realizadas por participante, de apenas uma frase. Todavia, o presente estudo tem por objetivo demonstrar o processo de editar micro e macroUTs; para tal, utiliza-se dos dados de um dos participantes da pesquisa de Minatogau.

\subsection{Origem dos dados e método}

Os dados utilizados são provenientes de apenas um dos participantes (P3) da pesquisa realizada por Minatogau (2018): estudante que obteve, em um curto tempo, mais proficiência em língua japonesa. Pela diferença tipológica entre as línguas, os alunos brasileiros têm dificuldades para atingir o nível B1 de proficiência em língua japonesa (escala do QECR ${ }^{6}$ ). O aluno selecionado, excepcionalmente, obteve o nível 2 do Exame de Proficiência de Língua Japonesa $\left(\mathrm{JLPT}^{7}\right)$, consideravelmente equivalente a B1, já no segundo ano de estudo de japonês. Apesar da nossa expectativa de que P3 resolveria a tarefa sem deparar com as dificuldades, ele a realizou por meio de um processo complexo, o que dificultou nossa análise de dados.

\footnotetext{
${ }^{6} \mathrm{O}$ QECR é Quadro Europeu Comum de Referência para línguas (The Common European Framework of Reference for languages (CEFR)) que descreve níveis da proficiência no uso de línguas estrangeiras em comunicação. Detalhes são expostos no link: https://www.coe.int/en/web/common-europeanframework-reference-languages/level-descriptions.

${ }^{7}$ O JLPT representa The Japanese Language Proficiency Test que avalia e certifica a proficiência de falantes não nativos de língua japonesa. O exame é realizado anualmente no Brasil também. Os detalhes se encontram no link: https://jlpt.jp/e/about/purpose.html.
} 


\subsection{Tempo de pausa}

Minatogau (2018) realizou a pesquisa sem rastreamento ocular e adotou meio segundo (500 milissegundos [ms]) para a análise, pelos motivos arrolados a seguir:

1) esse é o valor mínimo medível do output do aplicativo MisroUnitsAPP;

2) a relação entre pausa e atenção, esta medida pelo rastreamento ocular, não está sendo explorada ainda. Quanto ao resultado dos dados do movimento ocular, Sekino (2015), em outro estudo, identificou 388 ms em média para a fixação dos olhos na tarefa de tradução pelos alunos avançados no mesmo par linguístico. A fixação é medida quando os olhos praticamente pausam para reconhecer e compreender uma palavra na leitura (RAYNER; 1998). Se a leitura de uma palavra seguir a produção imediata de seu "equivalente" na tradução, é possível que evidencie certo ritmo cognitivo na base do processo de tradução de palavra por palavra, a qual é plausível dentre os aprendizes do nível intermediário de japonês. A segmentação com pausa de meio segundo pode revelar, então, o reconhecimento e compreensão de uma palavra pelos participantes desse nível.

3) como não há um valor temporal da pausa estabelecido como indicador de esforço cognitivo (cf. KUMPULAINEN; 2015), o estudo de Minatogau (2018) adota uma abordagem heurística no sentido de testar se o valor escolhido revela alguma característica do comportamento cognitivo processual do participante. Concordando com Minatogau (2018) no que diz respeito à adoção do valor e buscando comparabilidade entre os resultados, mantevese, para nossa apresentação do método e procedimento de análise das micro e macroUTs, o valor de meio segundo.

\subsection{Os dados de tradução de $P 3$}

Apresenta-se, na Figura 1, a imagem da tela do Translog. 
Figura 1 - A tela do Translog-II no experimento de P3.

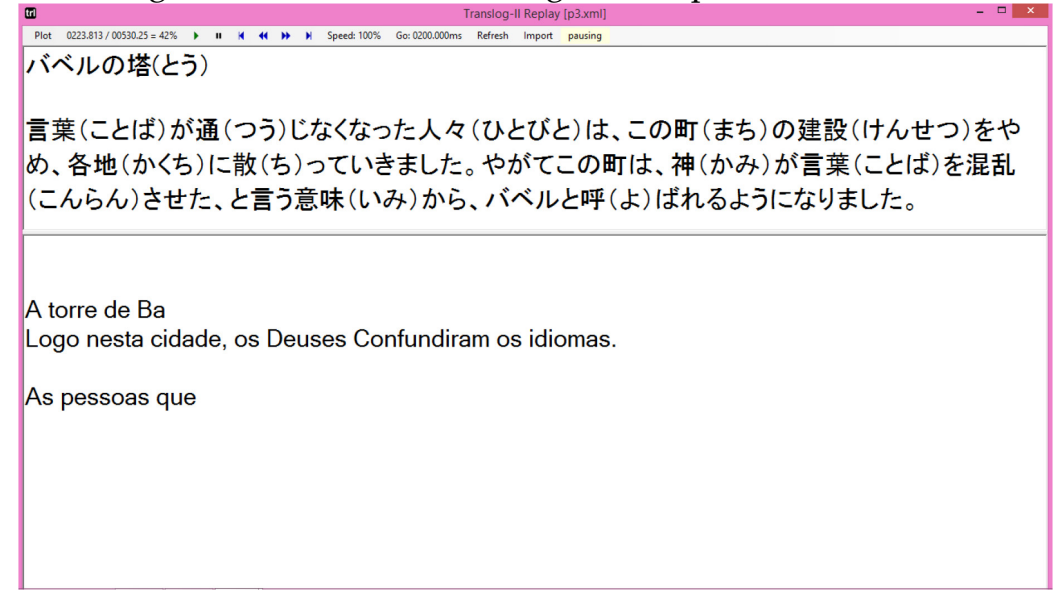

Minatogau (2018) dividiu a tela do Translog em duas: a superior para o TF e a inferior para o TA. De acordo com a métrica da língua japonesa, jReadability ${ }^{8}$, o TF possui 86 caracteres, e a sua dificuldade mede 3,5 pontos em escala de 1 a 6 , sendo 6 o mais difícil, ou seja, situa-se no ínterim intermediário inferior. Os caracteres chineses são fornecidos na leitura em japonês, entre parênteses, para facilitar a leitura dos estudantes. O TF é uma transcrição da narração de um programa de TV sobre o Antigo Testamento ${ }^{9}$. O significado do texto é:

\section{Torre de Babel}

As pessoas que não conseguiam mais se comunicarem pararam a construção dessa cidade e se espalharam por vários lugares. No fim, essa cidade veio a ser chamada de Babel, porque Deus causou a confusão das línguas. (tradução de MINATOGAU, 2018, p.12).

8 A métrica criada pela Universidade Nacional de Tsukuba do Japão. Disponível em: http://jreadability.net.

${ }^{9} \mathrm{O}$ programa, a série de capítulos 1 a 4, foi transmitido pelo NHK, canal japonês, durante maio de 2014 semanalmente a partir do 7 de maio. O texto fonte transcrito é: 言葉が通じなくなった人々はこの町 の建設をやめ、各地に散って行きました。やがて、この町は神が言葉を混乱させたという意 味から、バベルと呼ばれるようになりました。 
Usa-se o MicroUnitsApp para gerar a análise linear com 500 ms de pausa. Na Figura 2, a parte inicial da análise linear está marcada com as pausas acumulativas em vermelho. A produção, ou seja, algum tipo de movimento de teclas e/ou mouse, está registrada em azul ou verde, intercalado entre as duas pausas. Cada movimento nessa produção é uma microUT.

Figura 2 - Imagem da análise linear do MicroUnitsAPP (P3).

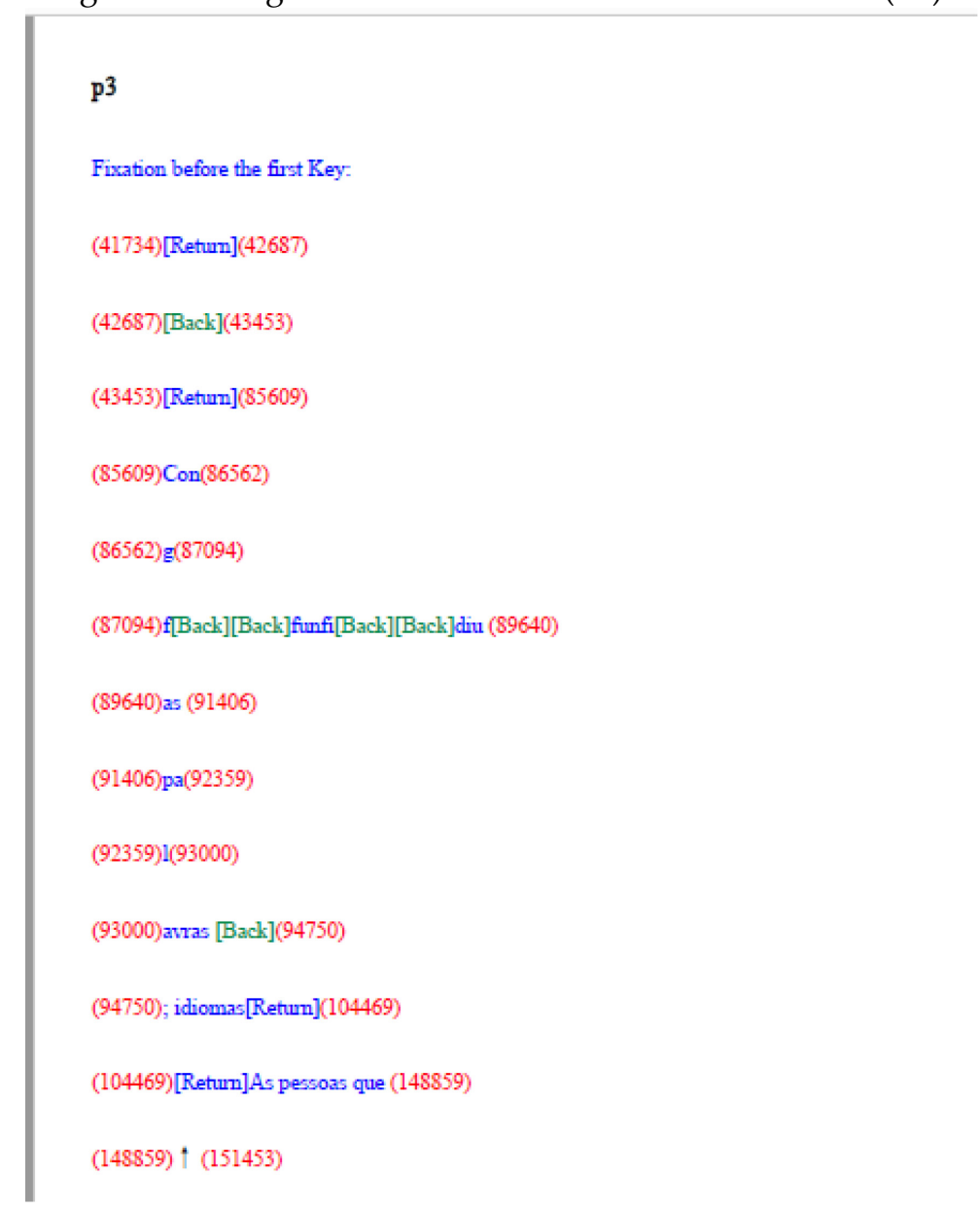

Em nosso estudo, analisando o número de microUTs, identificamos 96 UTs com pausas de duração variada. Daí, editamos tais microUTs, agrupando-as em macroUTs. Já na Figura 3, as edições foram implementadas com distanciamentos variados de margens para uma melhor visualização. Na microUT 4, por exemplo, o participante P3 começou a escrever o verbo "Confundir". Entendemos, a partir da microUT 4 até 6, 
que esse verbo não foi produzido por inteiro, mas de forma fragmentada (cf. LACRUZ; SHREVE; ANGELONE, 2012). Inclusive, algumas partes da palavra foram deletadas. Assim, para a tradução do verbo, as três microUTs foram necessárias, sendo 4 a microUT inicial, e 5 e 6 as microUTs subsequentes e necessárias para complementar e editar o verbo. A partir da microUT 7, a tradução dos trechos posteriores continua. Essas unidades foram editadas, ligadas às macroUTs anteriores e posteriores. Como resultado, foi criada a macroUT4, que consiste de mais de 70 microUTs. Conforme visto na revisão de literatura, o processo de tradução não é linear, mas consideravelmente recursivo, pois o tradutor retoma a produção anterior, às vezes engatilhado por alguma palavra que lhe aparece posteriormente.

Figura 3 - Edição de micro e macroUTs.

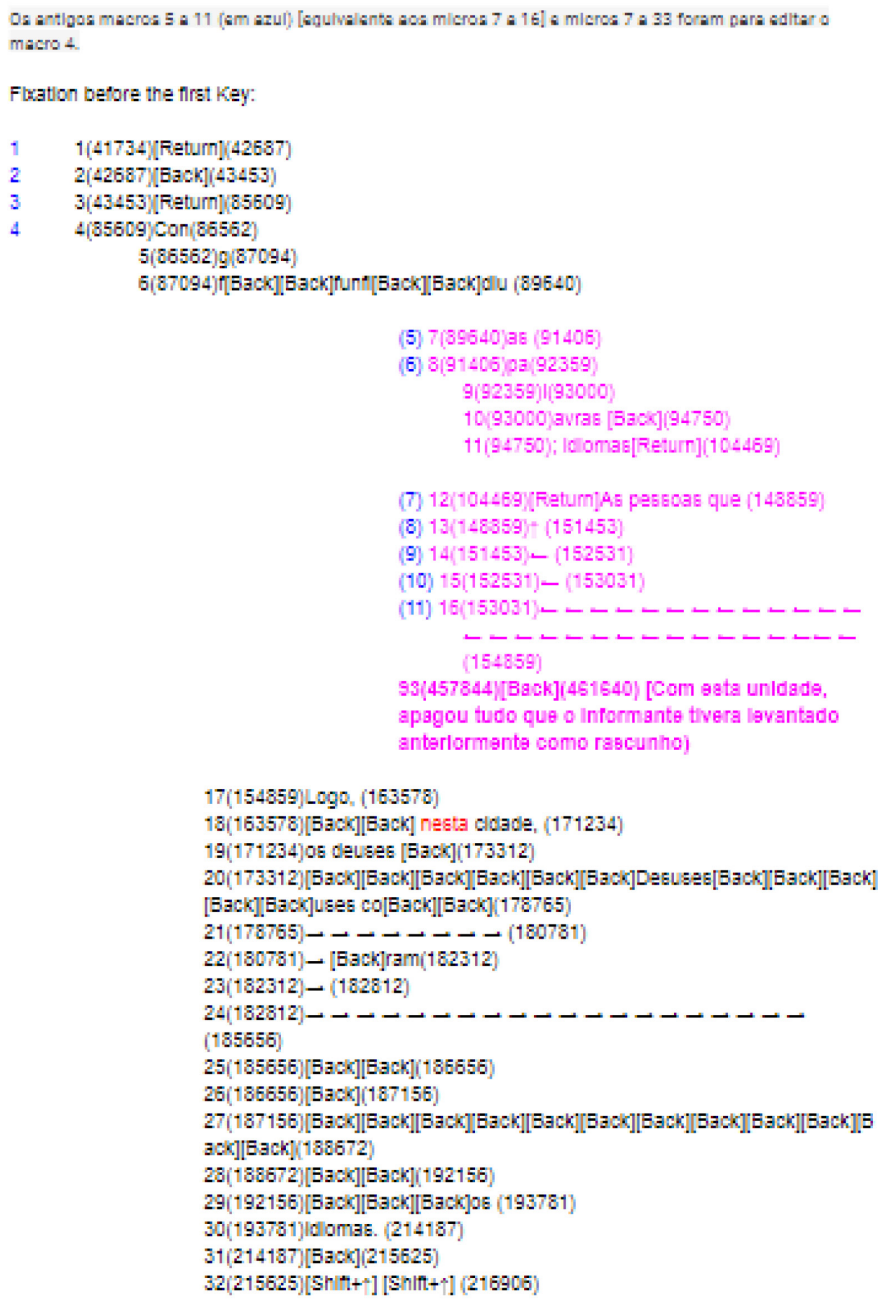


A Figura 4 demonstra, graficamente, o processo da produção. O gráfico apresenta a relação entre microUT (= mUT no eixo horizontal) e macroUT (= MUT no eixo vertical) por meio da frequência: como se comportam e sem considerar a duração. Entendemos, a partir do gráfico, que há diversos pontos na macroUT4, como vimos na Figura 3. Então, P3 dedicou-se, até certo ponto do texto, a várias edições, de maneira que a finalização do resto do texto foi rápida e fluida. Pode-se inferir, a partir dessa observação, que, enquanto P3 trabalhava em uma parte, ele entendia todo o significado do texto, não sendo necessárias retomadas, visto que, na parte final, é mais ou menos um processo linear.

Figura 4 - Gráfico da relação entre microUTs (mUT) macroUTs (MUT).

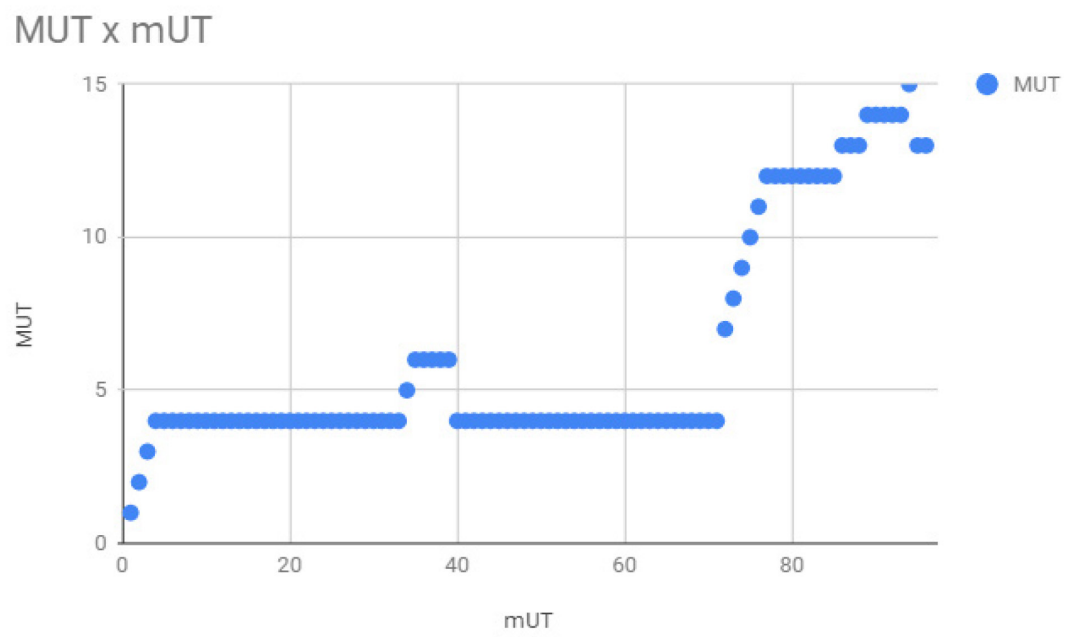

[O número da microUT no eixo vertical $(\mathrm{X})$ e o número da macroUT $1(\mathrm{Y})$.] 
Figura 5 - Gráfico da relação entre mUT e MUT, com o tempo adicionado

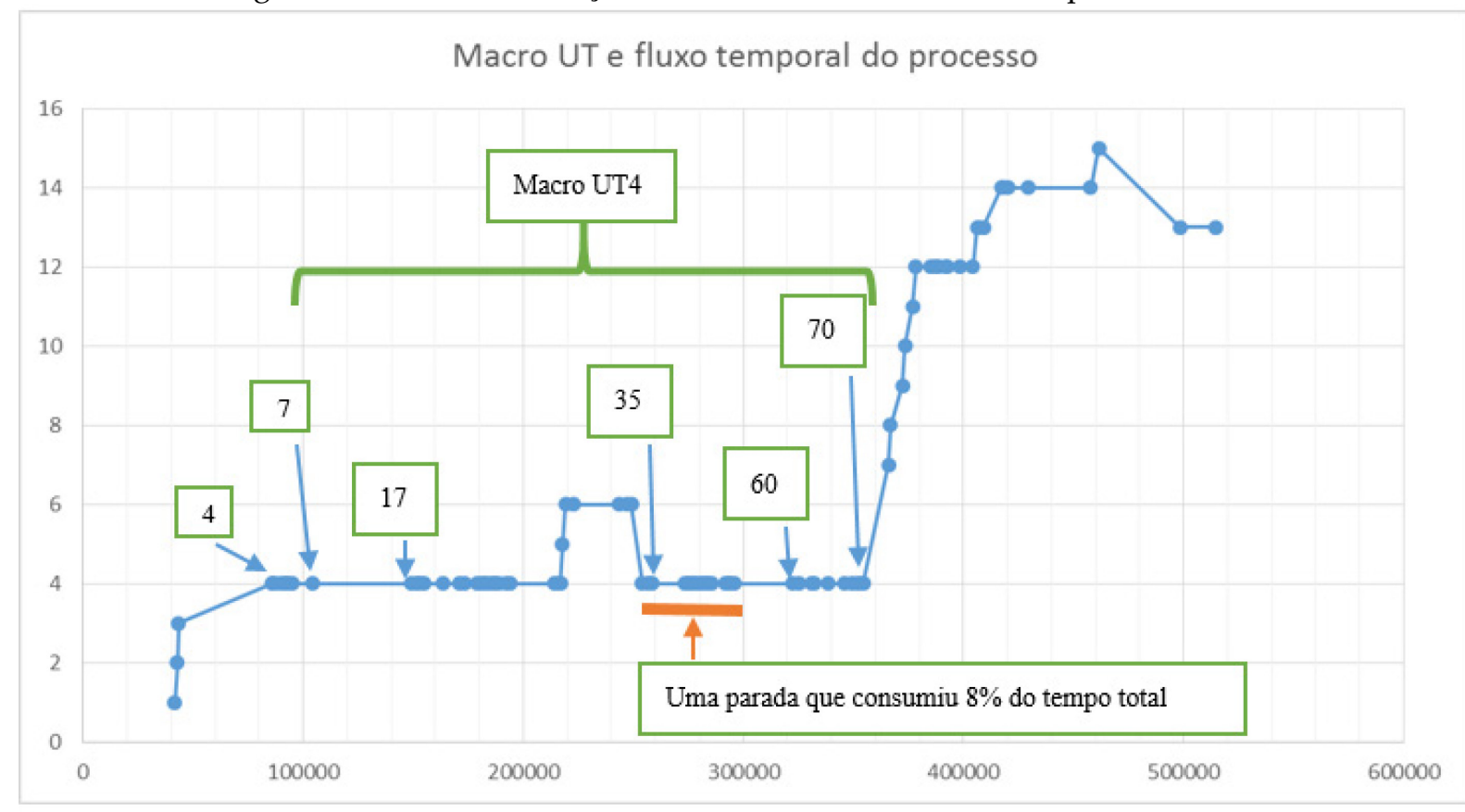

[O número da macroUT no eixo vertical $(\mathrm{Y})$ e o tempo no eixo horizontal $(\mathrm{X})$. Os números na gráfica representam as microUTs dentro da macroUT 4.]

Com o tempo adicionado, podemos ver que o trecho envolvido na macroUT 4 tomou quase três-quartos da produção total, tendo da microUT 4 à microUT 33 e da microUT 40 à microUT 71. Essas 60 microUTs são processualmente relacionadas e, coincidentemente, correspondem a construção da tradução de uma sentença. Pode-se dizer que essa parte do texto requereu um esforço cognitivo maior.

Para uma análise pragmática, as seguintes mudanças textuais demonstram a forma como P3 muda o universo do trecho. Conforme vemos na Tabela 1, P3, na microUT15, tem duas linhas de produção: a primeira é uma espécie de rascunho da segunda sentença; a segunda é o início da primeira sentença. Nessa unidade, não sabemos ainda se P3 "anotou", na primeira linha, algumas palavras-chave que lhe vieram à mente e/ou se ainda queria continuar a primeira sentença após o trecho "As pessoas que". 
Tabela 1 - Alguns pontos do processo da produção textual observados na microUT4.

\begin{tabular}{|c|c|c|}
\hline microUT & $\begin{array}{l}\text { Texto produzido na tela da tradução do Translog no fim da } \\
\text { segmentação de cada microUT. }\end{array}$ & $\begin{array}{l}\text { Tempo inicial da } \\
\text { mUT (ms) }\end{array}$ \\
\hline 4 & Con & 85609 \\
\hline 7 & Confundiu as & 89640 \\
\hline 11 & Confundiu as palavras; idiomas & 94750 \\
\hline 12 & $\begin{array}{l}\text { Confundiu as palavras; idiomas } \\
\text { As pessoas que }\end{array}$ & 104469 \\
\hline $13-14$ & \multicolumn{2}{|l|}{$148859 \mathrm{~ms}$ - 154859 ms (produção parada com movimento de setas) } \\
\hline 17 & $\begin{array}{l}\text { Logo Confundiu as palavras; idiomas } \\
\text { As pessoas que }\end{array}$ & 154859 \\
\hline 30 & $\begin{array}{l}\text { Logo nesta cidade, os Deuses Confundiram os } \\
\text { idiomas. } \\
\text { As pessoas que }\end{array}$ & \\
\hline 35 & $\begin{array}{l}\text { A torre de Bebel } \\
\text { Logo nesta cidade, os Deuses Confundiram os } \\
\text { idiomas. } \\
\text { As pessoas que }\end{array}$ & 193781 \\
\hline $40-60$ & \multicolumn{2}{|c|}{$\begin{array}{l}254109 \mathrm{~ms}-281609 \mathrm{~ms} \text { (produção parada com movimento de setas) } \\
\text { Aproximadamente } 41781 \mathrm{~ms} \text { de duração que corresponde a } 8 \% \text { do tempo total da tarefa }\end{array}$} \\
\hline 60 & $\begin{array}{l}\text { Logo esta cidade, em que } \\
\text { os Deuses Confundiram os idiomas. } \\
\text { As pessoas que }\end{array}$ & 294328 \\
\hline 70 & $\begin{array}{l}\text { Logo esta cidade, em que Deus confundiu as palavras, passou a ser } \\
\text { chamada de Torre de Babel. } \\
\text { os Deuses Confundiram os idiomas. } \\
\text { As pessoas que }\end{array}$ & 353422 \\
\hline
\end{tabular}

Na microUT 30 na Tabela 1, P3 acrescentou mais trechos antes da produção anterior verificada na microUT 17. A partir dessa produção, entende-se que P3 decidiu trabalhar com a segunda sentença, deixando a primeira para depois. Outro ponto relevante é que P3 traduziu o texto em ordem inversa. Se ele estivesse fazendo isso conscientemente, isso significaria que estava ciente da diferença sintática entre o japonês e o português-brasileiro. Ao traduzir a parte final, marcada por um verbo, P3, 
em virtude da estrutura SOV, usou uma estratégia, que é esclarecer o significado a partir da ação (verbo).

Na microUT 56, P3 dividiu a sentença em duas linhas, conforme vista na microUT 60 da Tabela 1. A partir dessa microUT 60, P3 acelerou a velocidade da tradução e mudou a estrutura da sentença, acrescentando mais palavras, como observamos na microUT 70. Ressalta-se que P3 não parou a produção da microUT60 a 70, embora se observe uma parada, apenas, com movimentos com as setas, que consumiu $8 \%$ do tempo total despendido da tarefa. Ao completar a segunda sentença, P3 não apagou o trecho "os Deuses Confundiram os idiomas", o qual foi reescrito. Contudo, foi possível perceber discrepâncias: "O Deus" e “os Deuses", assim como "palavras" e "idiomas". Essa parte demonstra a consciência de P3 sobre sua capacidade de memorização durante o trabalho - se apagasse o rascunho, ele poderia esquecer. De certa forma, mesmo completando a segunda sentença, ele preferiu deixar como referência o que escrevera intuitivamente, na primeira instância. Igualmente, com relação ao trecho "As pessoas que", no final da tela, ele repetiu as mesmas palavras em uma linha de cima acima, ou seja, no local correto onde essa sentença deveria iniciar.

O tempo da produção até a UT 70 foi aproximadamente $70 \%$ do tempo de produção total. Pode-se dizer, a partir dessa observação, que o restante da produção foi rápido: P3 completou a primeira sentença em 30\% do tempo da produção total despendido durante a tarefa. Logo, pode-se inferir que o processo para a resolução da segunda sentença fez P3 ler e reler a primeira sentença. Ao terminar essa segunda sentença, ele provavelmente já tinha a tradução da primeira em mente. Esse comportamento de P3 pode ser interpretado da seguinte forma: o processo de tradução da segunda sentença deve ter funcionado para recuperar as informações do contexto exposto em todo o TF. Apesar do tempo despendido na segunda sentença, $70 \%$, esse 
processo, concomitantemente, envolveu o esclarecimento da primeira. Assim sendo, não foi preciso despender tanto tempo para a elaboração da primeira.

A importância do contexto é ressaltada na Teoria da Relevância (SPERBER; WILSON, 1986). A análise das micro e macroUTs demonstra como se altera o ambiente cognitivo do tradutor durante a tarefa de tradução. Ao longo da tarefa, o ambiente cognitivo de P3 fica, cada vez mais, desenvolvido devido ao contexto do texto esclarecido.

Nota-se que o problema semântico pode ter causado uma confusão pragmática, como visto no léxico japonês de “ $\square \square(k o t o b a)^{\prime}$, substantivo, que ocorre duas vezes e ensejou dificuldades a P3. A palavra "kotoba" significa "palavra" em japonês, mas também pode ser compreendida como "idioma", especialmente por causa do verbo que a segue na primeira sentença, " $\square \square \square$ "("tsuujiru", cujo significado é "passar"). Com o uso desse verbo, a palavra "kotoba", na maioria das vezes, deve ser interpretada como "língua" ou "idioma", em vez de "palavra", de uso convencional. No entanto, para isso, precisa-se de um esforço para essa interpretação devido à adequação estrutural dessa parte, que requer, por meio do processamento cognitivo, uma conclusão implicada - em vez de deixá-la como está, "palavra passa" -, haja vista que, no japonês, significa, “(tal) língua é usada para se comunicar"..

No momento da observação dessa microUT, parece que P3 não obteve, de pronto, esse esclarecimento de conclusão implicada, já que deixou, à vista, o rascunho dos dois sentidos. Esse comportamento pode ser explicado da seguinte forma: após escrever, na primeira instância, as duas opções equivalentes para esse termo, P3 priorizou a leitura contextual a fim de escolher a melhor palavra para tradução. Independentemente da adequação da escolha, P3 recuperou o uso da língua e do contexto, talvez por meio da memória de longo prazo.

Algumas UTs, como uma pequena macroUT cujos microUTs não foram retomadas posteriormente ou uma microUT isolada, podem ser entendidas como uma 
parte já resolvida do texto, para a qual não houve concentração de atenção pelo informante. No entanto, se o informante estruturar um trecho de tradução com um grande número de microUTs, isso pode indicar que algo ainda precisa ser resolvido para codificar os segmentos em questão de maneira que reflitam melhores efeitos contextuais. Enquanto traduz interseccionando com outras microUTs, P3 busca o esclarecimento contextual para uma melhor tradução. Assim, ao longo do trecho, dentro de uma microUT, pode haver a indicação de que o informante já tem uma clareza do contexto, do significado e da tradução. Nesse sentido, a tradução pode ser processada na mente, sendo: digitada rapidamente sem pausas expressivas, quando essa tradução do segmento é bastante clara; ou digitada lentamente, segmentada frequentemente, quando a tradução do segmento é ainda obscura, buscando solução. Isso reflete a relação da capacidade da memória de trabalho relativa ao processamento cognitivo e aos tipos de trechos textuais. Isso porque alguns trechos do texto dificultam, ao tradutor, a busca de contextos semelhantes para construir a tradução.

O esforço cognitivo do informante se refere, então, à busca por contexto semelhante ao da cultura-alvo (GUTT, 1992); assim, se a recuperação que envolve a memória de longo prazo demorar, o informante terá de recuperá-lo a partir da construção da tradução. A partir dessa observação, pode-se dizer que há dois tipos de tradução, por analogia, referindo-se a estratégias de leitura (NUNAN, 1991): top-down, em que a manifestação linguística do TF é compreendida a partir da ciência e do conhecimento prévio do contexto; e a bottom-up, em que o tradutor recupera o contexto a partir da decodificação e reconstrução do TF.

No PVR, P3 comentou apenas os problemas linguísticos. Uma vez que o objetivo de Minatogau (2018) foi a observação da compreensão da estrutura da oração adjetiva do japonês pelos alunos do curso, sua pesquisa não era dedicada a observar o comportamento deles como tradutores. Em nosso estudo, conforme esperado, P3 concentrou-se na tradução a partir da decodificação do TF sem o acesso ao contexto, 
uma vez que ele não teve a bagagem de conhecimento sobre a história. Pelo exposto, especialmente do desenvolvimento de micro e macroUTs, o processo tradutório observado nesse tipo de análise se alinha com outros dados, incluindo os de PVR.

\section{Considerações finais}

Exploramos os dados de P3, no que diz respeito ao processo de tradução registrado no Translog-II e mediante análise a partir do MicroUnitsApp. Parece-nos que ainda há mais espaço a ser explorado por meio das micro e macroUTs a fim de identificar a sequência de pensamentos e o processo de recuperação do contexto do tradutor quando se tornam visíveis na construção da tradução registrada no Translog. Os segmentos textuais de rascunho, apagados e até erros de digitação podem ser analisados como pistas observáveis de esforço cognitivos e do processo de recuperação do contexto. Conforme indicado por Alves e Gonçalves (2013), é razoável entender que uma macroUT, proveniente da agregação de um grande número de microUTs indica esforço cognitivo. Além disso, os resultados de P3 sugerem que, durante o processamento de um segmento ou uma sentença, envolvem-se leitura e processamento cognitivo em um período amplo (na Tabela 1, a parada de $41781 \mathrm{~ms}$, ou seja, 41,8 segundos) na produção das micro UTs 40 a 60 .

Como verificado em P3, que despendeu 70\% do tempo para a resolução da segunda sentença e $12 \%$ para a primeira sentença, ele investiu no esclarecimento do contexto enquanto trabalhava na segunda sentença. Assim, esse processo facilitou a P3 o esclarecimento contextual; logo, facilitou a tradução da primeira sentença. A partir da nossa observação, podemos concluir que a investigação do processo de tradução, com o uso de micro e macroUTs, demonstra o processo do tradutor na recuperação e na recriação do contexto, situação e cultura do TF, além do processo de codificar a semelhança interpretativa (GUTT; 2000) no TA. 
Para finalizar, registramos uma preocupação: apesar do potencial de análise das micro e macroUTs, ainda se faz necessária uma ferramenta para editá-las eficientemente, com o intuito de exploração dos dados, inclusive no que diz respeito a pesquisas quantitativas. Acreditamos que a análise é válida, uma vez que pode trazer resultados qualiquantitativos que outros métodos não conseguiram trazer. A análise conjunta com os dados do rastreamento ocular pode esclarecer alguns processos que ainda não foram percebidos e comprovados. Nesse sentido, é urgente o desenvolvimento de um editor de UTs a fim de observar o funcionamento da cognição relativa à recuperação do contexto durante a tarefa de tradução, o processamento nas memórias, a relação língua e cultura na tradução e os detalhes do esforço cognitivo no processo de tradução.

\section{Referências}

ALVES, F. Zwischen Schweigen und Sprechen: Wie bildet sich eine transkulturelle Brücke?: eine psycholinguistisch orientierte Untersuchung von Übersetzungsvorgängen zwischen portugiesischen und brasilianischen Übersetzern. Hamburg: [s.n.], 1995. apud RODRIGUES, C. A abordagem processual no estudo da tradução: uma meta-análise qualitativa. Caderno de Tradução, Florianópolis, v. 2, n. 10, p. 22-33, 2002.

ALVES, F. A triangulação como opção metodológica em pesquisas empíricoexperimentais em tradução. In: ADRIANA, P. S. Metodologias de pesquisa em tradução. Belo Horizonte: FALE-UFMG, 2001. p. 69-92.

ALVES, F. Tradução, cognição e contextualização: Triangulando a interface processoproduto no desempenho de tradutores novatos. D.E.L.T.A., São Paulo, n. 19 especial, p. 71-108, 2003. DOI https://doi.org/10.1590/S0102-44502003000300006.

ALVES, F.; GONÇALVES, J. L. Modelling translator's competence: Relevance and expertise under scrutiny. In: GAMBIER, Y.; SHLESINGER, M.; STOLZE, R. Doubts and Directions in Translation Studies: Selected contributions from the EST Congress, Lisbon, 2004. Amsterdam: John Benjamins, 2007. p. 41-55. DOI https://doi.org/10.1075/btl.72.07alv. 
ALVES, F.; GONÇALVES, J. L. Investigating the conceptual-procedural distinction in the translation process: a relevance-theoretic analysis of micro and macro translation units. Target, v. 24, n. 1, p. 107 - 124, 2013.

ALVES, F.; PAGANO, A.; MAGALHÃES, C. Traduzir com autonomia: estratégia para o tradutor em formação. São Paulo: Contexto, 2000.

ALVES, F.; VALE, D. C. Probing the unit of translation in time aspects of the design and development of a web application for storing, annotating and querying translation process data. Across Languages and Cultures, v. 10, n. 2, p. 251-273, 2009. DOI https://doi.org/10.1556/Acr.10.2009.2.5.

ALVES, F.; VALE, D. C. On drafting and revision in translation: a corpus linguisticsoriented analysis of translation process data. Translation: Corpora, Computation, Cognition. Special Issue on Parallel Corpora: Annotation, Exploitation, Evaluation. Journal of Corpus Linguistics, v. 1, n. 1, p. 105-122. 2011.

ALVES, F; PAGANO, A.; NEUMANN, S.; STEINER, E.; HANSEN-SCHIRRA, S. Translation units and grammatical shifts: Towards an integration of product- and process-based translation research. In: SHREVE, G.; ANGELONE, E. (org.). Translation and Cognition. Amsterdam: John Benjamins, 2010. v. 1, p. 109-142. DOI https://doi.org/10.1075/ata.xv.07alv.

BADDELEY, A. Working memory, thought and action. New York: OUP, 2007. DOI https://doi.org/10.1093/acprof:oso/9780198528012.001.0001.

BADDELEY, A. D.; HITCH, G. J. Working memory. In: BOWER, G. A. (ed.) The Psychology of Learning and Motivation. Academic Press, 1974. p. 47-89. DOI https://doi.org/10.1016/S0079-7421(08)60452-1.

BALLARD, M. Unit of translation. In: GAMBIER, Y. (ed.) Handbook of Translation. Amsterdam: John Benjamin, 2010. DOI https://doi.org/10.1075/hts.1.uni1.

BASSNETT-MCGUIRE, S. Translation Studies. revised ed. London: Routledge, 1991.

BELL, R. Translation and Translating: theory and practice. London: Longman, 1991.

CARL, M. Translog-II: A program for recording user activity data for empirical translation process research. IJCLA, v. 3, n. 1, p. 153-162, jan.-jun. 2012. 
CARL, M.; DRAGSTED, B.; JAKOBSEN, A. L. A Taxonomy of Human Translation Styles. Translation Journal, v. 16, n. 2, 2011. Disponível em: https://translationjournal.net/journal/56taxonomy.htm

CATFORD, J. C. Linguistic theory of translation. Oxford: OUP, 1964.

COOPER, G. Research into cognitive load theory and instructional design at UNSW. 1998. Disponível em: http://dwb4.unl.edu/Diss/Cooper/UNSW.htm. Acesso em: 30 out. 2018.

DA SILVA, I. et al. Translation, post-editing and directionality: A study of effort in the Chinese-Portuguese language pair. In: JAKOBSEN, A. L.; MESA-LAO, B. Translation in Transition: Between cognition, computing and technology. John Benjamins, 2017. p.108-137. DOI https://doi.org/10.1075/btl.133.04lou.

DRAGSTED, B. Segmentation in translation and translation memory system: An empirical investigation of cognitive segmentation and effects of integrating a TM system into the translation process. 2004. 369 f. Tese (Doutorado) - Copenhagen Business School, Copenhagen, 2004.

DRAGSTED, B. Segmentation in translation: Differences across levels of expertise. Target, Amsterdam, v. 17, n. 1, p. 49-70, 2005. DOI https://doi.org/10.1075/target.17.1.04dra.

EHRENSBERGER-DOW, M.; DANIEL P. Applying newswriting process research to translation. Target, v. 25, n. 1, p. 77-92, 2013. DOI https://doi.org/10.1075/target.25.1.07ehr.

ERICSSON, K. A.; SIMON, H. A. Protocol Analysis: Verbal Reports as Data. London: The MIT Press, 1993.

FERREIRA, A. Analyzing recursiveness patterns and retrospective protocols of professional translators in L1 and L2 translation tasks. Translation and Interpreting Studies, v. 9, n. 1, p. 109-127, 2014. DOI https://doi.org/10.1075/tis.9.1.06fer.

FERREIRA, A. Investigando o processamento cognitivo de tradutores profissionais em tradução direta e inversa no par linguístico inglês português. Cadernos de Tradução, v. 29, p. 73-92, 2012. DOI https://doi.org/10.5007/2175-7968.2012v1n29p73.

FERREIRA, A; SCHWIETER, J. W.; GOTTARDO, A.; JONES, J. Cognitive effort in direct and inverse translation performance: insight from eye-tracking technology. 
Caderno de Tradução, v. 36, n. 3, p. 60-80, 2016. DOI https://doi.org/10.5007/21757968.2016v36n3p60.

FINGER-KRATOCHVIL, C. Estratégias para o desenvolvimento da competência lexical: relações com a compreensão em leitura. 2010. 677 f. Tese (Doutorado em Letras) - Universidade Federal de Santa Catarina, Santa Catarina, 2010.

FONSECA, N. Pós-edição monolíngue: uma análise de indicadores de dispêndio de esforço temporal, técnico e cognitivo. 2016. 231. f. Tese (Doutorado em Estudos Linguísticos) - Faculdade de Letras, Universidade Federal de Minas Gerais, 2016.

GOOD, D.; BUTTERWORTH, B. Hesitation as a conversational resource. In: DECHERT, H.; RAUPACH, M. (ed.). Temporal Variables in Speech. Mouton: The Hague, 1980.

GUTT, E. A. Translation and relevance: Cognition and context. Manchester: St Jerome, $1991 / 2000$.

GUTT, E. A. Relevance theory: A guide to successful communication in translation. New York: Summer Institute of Linguistics, 1992

GUTT, E. A. Issues of translation research in the inferential paradigm of communication. In: OLOHAN, M. (ed.). Intercultural Faultlines: Research Models in Translation Studies 1: Textual and Cognitive Aspects. Manchester: St. Jerome, 2000. p. 161-179. DOI https://doi.org/10.4324/9781315759951-11.

HANSEN, G. The dialogue in translation process research. Translation and Cultural Diversity. In: Translators Association of China (ed.). XVIII FIT World Congress Proceedings, 2008. Foreign Languages Press, 2009. p. 386-397.

HERMANS, T. Translation in Systems: Descriptive and system-oriented approaches explained. Manchester: St. Jerome, 1999.

HOLMES, J. S. The name and nature of Translation Studies. In: HOLMES, J. Translated! Papers on Literary Translation and Translation Studies. Amsterdam: Rodopi, 1972. p. 67-80.

HVELPLUND, K. T. Allocation of cognitive resources in translation: an eye-tracking and key-logging study. 2011. 276. f. Tese (Doutorado) - Copenhagen Business School, Copenhagen, 2011. 
IMMONEN, S. Translation as a writing process: Pauses in translation versus monolingual text production. Target, 18, n. 2, p. 313-336, 2006. DOI https://doi.org/10.1075/target.18.2.06imm.

IMMONEN, S. Unravelling the processing units of translation. Across Languages and Cultures, v. 12, n. 2, p. 235-257, 2011. DOI https://doi.org/10.1556/Acr.12.2011.2.6.

KOGLIN, A. Efeitos cognitivos e esforço de processamento de metáforas em tarefas de pós-edição e de tradução humana: uma investigação processual à luz da teoria da relevância. 2015. 196. f. Tese (Doutorado em Estudos Linguísticos) - Faculdade de Letras, Universidade Federal de Minas Gerais, 2015.

KUMPULAINEN, M. On the operationalisation of 'pauses' in translation process research. Translation \& Interpretation, v. 7, n. 1, p. 47-58, 2015.

MILLER, G. The magical number seven, plus or minus two: some limits on our capacity for processing information. The psychological review, 63 (2). Washington: APA, 1956. p. 81-97. DOI https://doi.org/10.1037/h0043158.

JAKOBSEN, A. L. Logging target text production by Translog. In: HANSEN, G. (ed.), Probing the process in translation: methods and results. Copenhagen Studies in Language, v. 24, p. 9-20, 1999.

JAKOBSEN, A. L. Translation drafting by professional translators and by translation students. In: SÁNCHEZ TRIGO, E.; FOUCES, O. D. Traducción \& Comunicación. Vigo: Universidad de Vigo, 2002. p. 89-103.

JAKOBSEN, A. L. Effects of think aloud on translation speed, revision and segmentation. In: ALVES, F. Triangulating Translation. Perspectives in Process Oriented Research. Amsterdam: John Benjamin, 2003. p. 69-95. DOI https://doi.org/10.1075/btl.45.08jak.

JAKOBSEN, A. L. Instance of peak performance in translation. Lebende Sprachen, v. 3, p. 9-20, 2005. DOI https://doi.org/10.1515/LES.2005.111.

JAKOBSEN, A. L. Investigating expert translators' processing knowledge. In: HELLE, V. Dam et al. Knowledge systems and translations. Mouton de Gruyter: The Hague, 2005. p. 173-189.

JAKOBSEN, A. L. Tracking Translators' Keystrokes and Eye Movements with Translog. In: ALVSTAD, C.; HILD, A.; TISELIUS, E. (ed.). Methods and Strategies of 
Process Research: Integrative Approaches in Translation Studies, Amsterdam: John Benjamin, 2011. p. 37-55. DOI https://doi.org/10.1075/bt1.94.06jak.

JAKOBSEN, A. L.; JENSEN K. T. H. Eye movement behaviour across four different types of reading task. In: GÖPFERICH, S.; JAKOBSEN, A. L.; MEES, I. M. (ed.). Looking at Eyes: Eye-Tracking Studies of Reading and Translation Processing. Copenhagen: Samfundslitteratur, 2008. p.103-124.

KOEHN, P.; HADDOW, B. Interactive Assistance to Human Translators using Statistical Machine Translation Methods. In: MT Summit XII The twelfth Machine Translation Summit, Ottawa, Ontario, Canada, 26/08/2009. Proceedings... 2009. p. 1-8.

KRINGS, H. P. Was in den Köpfen von Übersetzern vorgeht. Eine empirische Untersuchung zur Struktur des Übersetzungsprozesses an fortgeschrittenen Französischlernern. Tübingen: Narr, 1986. apud RODRIGUES, C. A abordagem processual no estudo da tradução: uma meta-análise qualitativa. Caderno de Tradução, Florianópolis, v. 10, n. 2, p. 22-33, 2002.

KÜNZLI, A. Experts versus novices: 1'utilisation de sources d'information pendant le processus de traduction. Meta, v. 46, n. 3, p. 507-523, 2001.

KÜNZLI, A. Risk taking: trainee translators vs. professional translators. A case study. The Journal of Specialised Translation, v. 2, p. 34-49, 2004. DOI https://doi.org/10.7202/003363ar.

LACRUZ, I.; SHREVE, G. M.; ANEGLONE, E. Average Pause Ratio as an indicator of cognitive effort in post-editing: A case Study. In: O'BRIEN, S.; SIMARD, M.;SPECIA, L. (ed.). AMTA 2012 WORKSHOP ON POST-EDITING TECHNOLOGY AND PRACTICE, San Diego. Proceedings... San Diego: 2012. p. 20-29.

LACRUZ, I.; SHREVE, G.M. Pauses and cognitive effort in post-editing. In: O'BRIEN, S.; WINTHER BALLING, L.; CARL, M.; SIMARD, M.; SPECIA, L. (ed.). Post-editing of machine translation: processes and applications. Cambridge: Cambridge Scholars, 2014. p. 244-272.

LANGENDOEN, D. T. Eugene Albert Nida [versão de pré-publicação]. Language, 89. p. 163-169. jan. 2013. DOI https://doi.org/10.1353/lan.2013.0008.

MINATOGAU, M. Análise da identificação de oração adjetiva em língua japonesa através do processo de tradução. 45. f. 2018. Trabalho de Conclusão de Curso (Letras) - Universidade de Brasília, Brasília, 2018. 
MOUNIN, G. Les probléms théorique de la traduction. Gillimard: Paris, 1963.

NEWMARK, P. A textbook of translation. Prentice Hall: New York, 1988.

NIDA, E. A. Science of translation. Language, v. 45, 1969. p.483-498. DOI https://doi.org/10.2307/411434.

NIDA, E. A. Toward a science of translating: with special reference to principals and procedures involved in Bible translating. Brill: Leiden, 1964.

NIDA, E. A.; TABER, C. R. The theory and practice of translation. Brill: Leiden, 1969. DOI https://doi.org/10.2307/411434.

NINOMIYA, S. R. L. Estruturação temática na tradução de textos literário da língua japonesa para a língua portuguesa: um enfoque Sistêmico-Funcional. 194 f. 2012. Tese (Doutorado em Linguística Aplicada aos Estudos da Linguagem) - Pontifícia Universidade Católica de São Paulo, São Paulo, 2012.

NUNAN, D. Language Teaching Methodology. Prentice Hall International: Hertfordshire, 1991.

RAYER, K. Eye movements in reading and information processing: 20 years of research. Psychol. Bull., v. 124, n. 3, p. 372-422, 1998. DOI https://doi.org/10.1037//0033-2909.124.3.372.

RODRIGUES, C. Processos mentais e ensino da tradução: uma revisão bibliográfica. Caderno de Tradução, Florianópolis, v. 1, n. 2, p.55-74, 1997.

RODRIGUES, C. A. Abordagem processual no estudo da tradução: uma meta-análise qualitativa. Caderno de Tradução, Florianópolis, v. 2, n. 10, p. 23-57, 2002.

SAGER, J. C. Language engineering and translation: Consequences of automation. Amsterdam: John Benjamin, 1994. DOI https://doi.org/10.1075/btl.1.

SCHILPEROORD, J. It's about time. Temporal aspects of cognitive processes in text production. Rodopi: Amsterdam/Atlanta, 1996.

SCHAEFFER, M.; CARL, M. Measuring the Cognitive Effort of Literal Translation Processes. In:WORKSHOP ON HUMANS AND COMPUTER-ASSISTED 
TRANSLATION, Gothenburg, Sweden, 26 abr. 2014. Proceedings.. Gothenbur: [s.e.], 2014. p. 29-37

SCHAEFFER, M.; CARL, M.; LACRUZ, I.; AIZAWA, A. Measuring Cognitive Translation Effort with Activity Units. Baltic Journal of Modern Computing, v. 4, n. 2, 2016. p. 331-345.

SCHMALTZ, M. Problem solving in the translation of linguistic metaphors from Chinese into Portuguese. In: WALKER, C.; FEDERICI, F. M. (ed.). Eye Tracking and Multidisciplinary Studies on Translation. Amsterdam: John Benjamins, 2018. p. 121144. DOI https://doi.org/10.1075/btl.143.07sch.

SCHMALTZ, M. et al Cohesive Relations in Text Comprehension and Production: An Exploratory Study Comparing Translation and Post-Editing. In: CARL M.; BANGALORE, S.; SCHAEFFER, M. (ed.). New Directions in Empirical Translation Process Research. New Frontiers in Translation Studies. Springer: Cham, 2016. p. 239-263. DOI https://doi.org/10.1007/978-3-319-20358-4_11.

SEKINO, K. Investigando processos de pós-edição e de tradução: uma análise cognitivo-pragmática da relação esforço/efeito no par linguístico japonês/português. 214. f. 2015. Tese (Doutorado em Estudos Linguísticos) - Faculdade de Letras, Universidade Federal de Minas Gerais, Belo Horizonte, 2015.

SHIBATANI, M. Japanese. In: COMRIE, B. (ed.). The world's major languages. 2. ed. Oxford: Routledge, 2009. p. 741-764.

SPEARBER, D.; WILSON, D. Relevance: communication and cognition. 2. ed. Oxford: Blackwell, 1986.

TOURY, G. In search of a theory of translation. Tel Aviv: Porter Institute for Poetics and Semiotics, 1980.

TOURY, G. What are Descriptive Studies into Translation Likely to Yield apart from Isolated Descriptions? In: VAN LEUVEN-ZWART, K. M.; NAAIJKENS, T. (ed.). Translation Studies: The State of the Art. Amsterdam \& Atlanta: Rodopi, 1991. p. 179192.

TOURY, G. Descriptive Translation Studies and beyond. Amsterdam: John Benjamins. 1995. DOI https://doi.org/10.1075/btl.4. 
TYLER, S. W.; HERTEL, P. T.; MCCALLUM, M. C.; ELLIS, H. C. Cognitive effort and memory. Journal of Experimental Psychology: Human Learning and Memory, v. 5, p. 607-617, 1979. DOI https://doi.org/10.1037/0278-7393.5.6.607.

VINAY, J.; DARBERNET, J. Comparative stylistic of French and English. A methodology for translation. Translated by Juan Carlos Sager. Amsterdam: John Benjamins, 1958/1995.

YOUNG, K. Direct from the source: the value of 'think-aloud' data in understanding learning. Journal of Educational Enquiry, v. 6, n. 1, p. 19-33, 2005.

YUS, F. Relevance Theory. In: HEINE, B.; NARROG, H. (ed.). The Oxford Handbook of Linguistic Analysis. Oxford: OUP, 2009. p. 753-778. DOI https://doi.org/10.1093/oxfordhb/9780199544004.013.0027.

WESTBROOK, A.; BRAVER, T. S. Cognitive effort: a neuroeconomic approach. Cogn Affect Behav Neurosci., v. 15, n. 2, p. 395-415, 2015. DOI https://doi.org/10.3758/s13415-015-0334-y.

ZHU, C. UT Once More: The sentence as the key functional unit of translation. Meta, v. 44, n. 3, 1999. DOI https://doi.org/10.7202/004644ar.

Aplicativo

DA SILVA, G. E. MicroUnitsAPP. Uberlândia: Universidade Federal de Uberlândia (UFU). 2015.2 Disponível em https://github.com/gabrieleduardo/MicroUnits.MicroUnitsAPP

APÊNDICE - Edição de microunidades de tradução - P3 (cf. MINATOGAU, 2018) 1(41734)[Return](42687) 2(42687)[Back](43453) 3(43453)[Return](85609) 4(85609)Con(86562) $5(86562) \mathrm{g}(87094)$ 6(87094)f[Back][Back]funfi[Back][Back]diu (89640)

(5) $7(89640)$ as (91406)

(6) 8(91406)pa(92359) 9(92359)1(93000) 10(93000)avras [Back](94750) 11(94750); idiomas[Return](104469)

(7) 12(104469)[Return]As pessoas que (148859)

(8) 13(148859)个 (151453)

(9) $14(151453) \leftarrow(152531)$

(10) $15(152531) \leftarrow(153031)$ 
(11) $16(153031) \leftarrow \leftarrow \leftarrow \leftarrow \leftarrow \leftarrow \leftarrow \leftarrow \leftarrow \leftarrow \leftarrow \leftarrow \leftarrow$

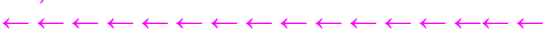

(154859)

93(457844)[Back](461640) [Com esta unidade, apagou tudo que o informante tivera levantado anteriormente como rascunho)

17(154859)Logo, (163578)

18(163578)[Back][Back] nesta cidade, (171234)

19(171234)os deuses [Back](173312)

20(173312)[Back][Back][Back][Back][Back][Back]Desuses[Back][Back][Back][Back][Back]uses

co[Back][Back](178765)

$21(178765) \rightarrow \rightarrow \rightarrow \rightarrow \rightarrow \rightarrow \rightarrow \rightarrow(180781)$

$22(180781) \rightarrow[$ Back]ram $(182312)$

23(182312) $\rightarrow(182812)$

24(182812) $\rightarrow \rightarrow \rightarrow \rightarrow \rightarrow \rightarrow \rightarrow \rightarrow \rightarrow \rightarrow \rightarrow \rightarrow \rightarrow \rightarrow \rightarrow \rightarrow \rightarrow \rightarrow \rightarrow \rightarrow(185656)$

25(185656)[Back][Back](186656)

26(186656)[Back](187156)

27(187156)[Back][Back][Back][Back][Back][Back][Back][Back][Back][Back][Back][Back](188672)

28(188672)[Back][Back](192156)

29(192156)[Back][Back][Back]os (193781)

30(193781)idiomas. (214187)

31(214187)[Back](215625)

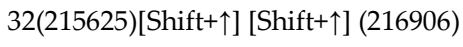

$33(216906) \leftarrow(217750)$

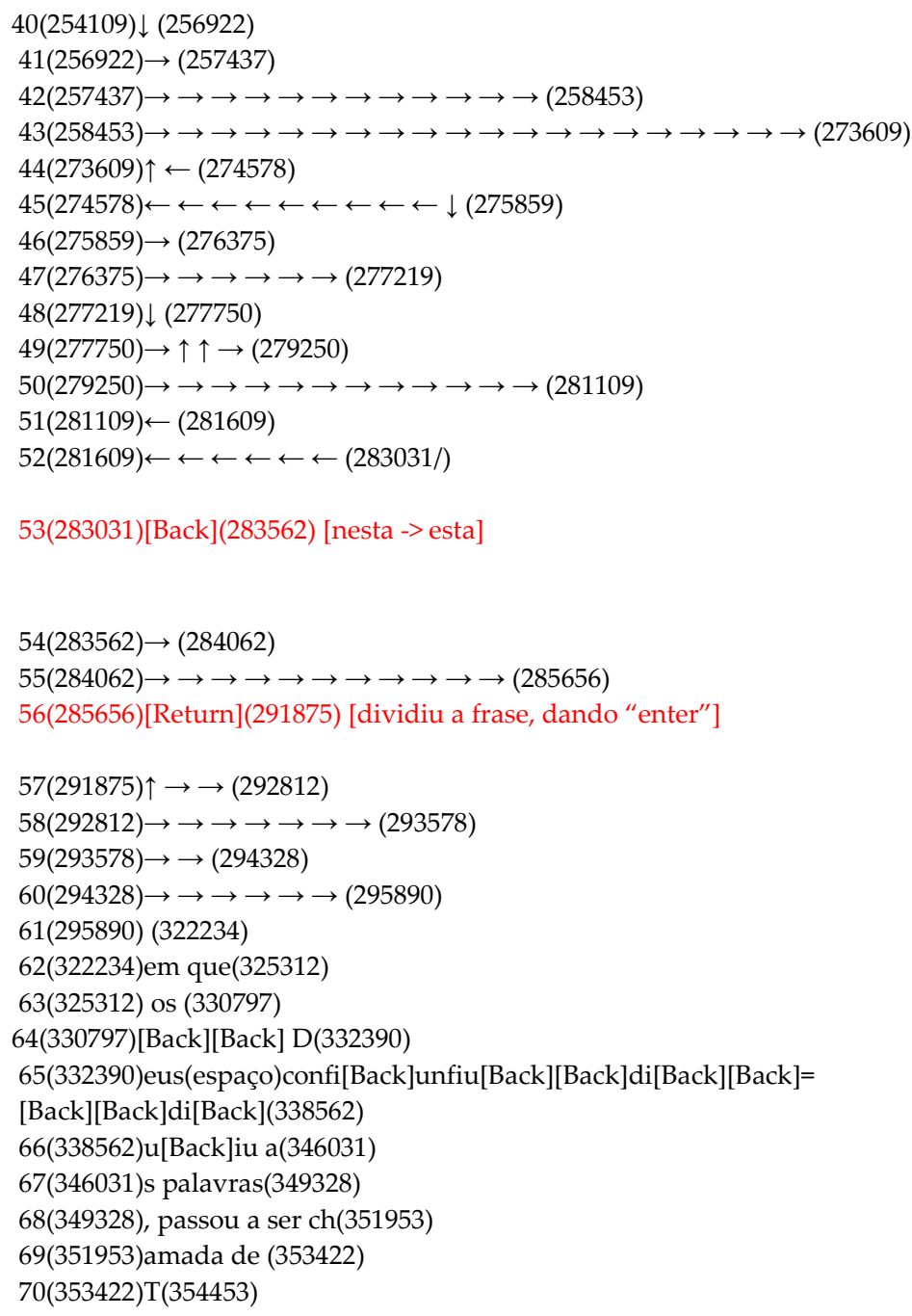


71(354453)orre De ba[Back][Back][Back][Back]d[Back][Back]de Babel.(366015)

5

8

9

10

11

$\leftarrow \leftarrow \leftarrow \leftarrow \leftarrow \leftarrow \longleftarrow$

$\leftarrow \leftarrow(154859)$ 7(89640)as (91406)

8(91406)pa(92359)

9(92359)1(93000)

10(93000)avras [Back](94750)

11(94750

); idiomas[Return](104469)

12(104469)[Return]As pessoas que (148859)

13(148859)^ (151453)

$14(151453) \leftarrow(152531)$

$15(152531) \leftarrow(153031)$

16(153031)

\section{7(154859)Logo, (163578)}

18(163578)[Back][Back] nesta cidade, (171234)

19(171234)os deuses [Back](173312)

20(173312)[Back][Back][Back][Back][Back][Back]Desuses[Back][Back][Back][Back][Back]

uses co[Back][Back](178765)

21(178765) $\rightarrow \rightarrow \rightarrow \rightarrow \rightarrow \rightarrow \rightarrow \rightarrow(180781)$

$22(180781) \rightarrow[$ Back $]$ ram $(182312)$

$23(182312) \rightarrow(182812)$

24(182812) $\rightarrow \rightarrow \rightarrow \rightarrow \rightarrow \rightarrow \rightarrow \rightarrow \rightarrow \rightarrow \rightarrow \rightarrow \rightarrow \rightarrow \rightarrow \rightarrow \rightarrow \rightarrow \rightarrow$ (185656)

25(185656)[Back][Back](186656)

26(186656)[Back](187156)

27(187156)[Back][Back][Back][Back][Back][Back][Back][Back][Back][Back][Back][Back]

$(188672)$

28(188672)[Back][Back](192156)

29(192156)[Back][Back][Back]os (193781)

30(193781)idiomas. (214187)

31(214187)[Back](215625)

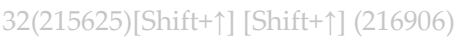

$33(216906) \longleftarrow(217750)$

512 34(217750)[Return][Return]A (219172)

613 35(219172)torre de Bebel (222562)

36(222562)[Back][Back][Back][Back][Back]abel (243422)

37(243422)c[Back][Back][Back][Back](247203)

38(247203)[Back](249265)

39(249265)[Back][Back][Back][Back][Back][Back][Back][Back][Back][Back][Back][Back][Back](254109)

$40(254109) \downarrow(256922)$

$41(256922) \rightarrow(257437)$

$42(257437) \rightarrow \rightarrow \rightarrow \rightarrow \rightarrow \rightarrow \rightarrow \rightarrow \rightarrow \rightarrow \rightarrow \rightarrow(258453)$

$43(258453) \rightarrow \rightarrow \rightarrow \rightarrow \rightarrow \rightarrow \rightarrow \rightarrow \rightarrow \rightarrow \rightarrow \rightarrow \rightarrow \rightarrow \rightarrow \rightarrow \rightarrow \rightarrow \rightarrow \rightarrow(273609)$

$44(273609) \uparrow \leftarrow(274578)$

$45(274578) \longleftarrow \leftarrow \longleftarrow \leftarrow \longleftarrow \longleftarrow \longleftarrow \longleftarrow \longleftarrow \downarrow(275859)$

$46(275859) \rightarrow(276375)$

$47(276375) \rightarrow \rightarrow \rightarrow \rightarrow \rightarrow \rightarrow(277219)$

$48(277219) \downarrow(277750)$

$49(277750) \rightarrow \uparrow \uparrow \rightarrow(279250)$

50(279250) $\rightarrow \rightarrow \rightarrow \rightarrow \rightarrow \rightarrow \rightarrow \rightarrow \rightarrow \rightarrow \rightarrow \rightarrow$ (281109)

$51(281109) \longleftarrow(281609)$

$52(281609) \longleftarrow \leftarrow \longleftarrow \leftarrow \longleftarrow \leftarrow(283031)$

53(283031)[Back](283562)

$54(283562) \rightarrow(284062$

$55(284062) \rightarrow \rightarrow \rightarrow \rightarrow \rightarrow \rightarrow \rightarrow \rightarrow \rightarrow \longrightarrow(285656)$

56(285656)[Return](291875)

$57(291875) \uparrow \rightarrow \rightarrow(292812)$

Domínios de Lingu@gem | Uberlândia | vol. 13, n. 2 | abr. - jun. 2019 ISSN 1980-5799 


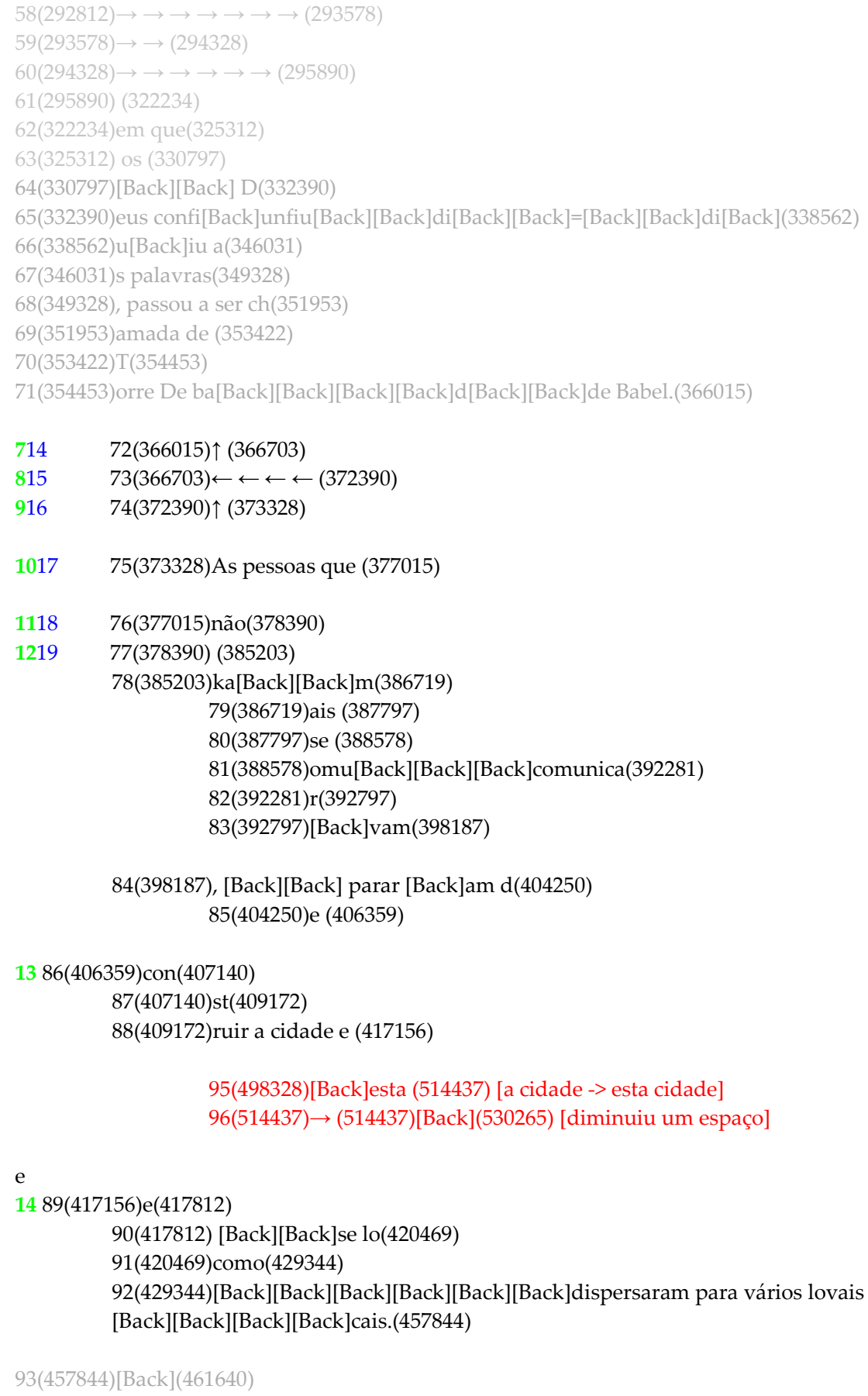

15 94(461640)[Back] (498328) (O espaço entre a primeira e segunda frase foi apagado. De fato, deveria colocar como microuT no local. Mas, se fizermos isso, temos que conectar toda produção e teríamos apenas uma microuT em toda a tradução.) 